\title{
Dissertações defendidas no Programa de Mestrado em Ciências da Saúde da Faculdade de Medicina do ABC
}

\section{A Avaliação da Aplicação do OSTEORISK em Mulheres na Pós-Menopausa e Osteoporóticas}

Autor: Marcelo Luis Steiner

Orientador: Prof. Dr. César Eduardo Fernandes Defesa: $10 / 12 / 2007$

Objetivo: O objetivo desse estudo foi avaliar a sensibilidade do Osteorisk em mulheres menopausadas com osteoporose. Método: Foram avaliadas 812 mulheres com média etária de 68,82 anos, em estudo retrospectivo. Foram analisadas as correlações entre os resultados da ferramenta clínica Osteorisk e o resultado da densitometria óssea nos sítios de coluna lombar e colo de fêmur. O índice de massa corpórea (IMC), além da comparação com o Osteorisk, foi relacionado com a densitometria óssea de coluna lombar e colo de fêmur, levando-se em conta diferentes faixas etárias. Ao final, pode-se concluir que o Osteorisk tem uma boa sensibilidade em identificar mulheres com risco para osteoporose. Essa sensibilidade é superior quando avaliado em relação ao colo de fêmur. A média do IMC teve uma associação significativa em relação ao Osteorisk. Ele foi significativo também quando avaliado em relação ao T-score de colo de fêmur nas faixas etárias de 50 a 59, 60 a 69 e 70 a 79 anos. Conclusão: Porém, não apresentou nenhuma relação significante na comparação com coluna lombar.
Correlação entre o Reposicionamento dos Parafusos Pediculares na Coluna Vertebral de Suínos e sua Força de Arrancamento: estudo de quarenta vértebras.

Autor: Luciano Miller Reis Rodrigues

Orientador: Prof. Dr. Carlo Milani

Defesa: 23/11/2007

Introdução: Este trabalho teve como objetivo estudar as alterações da força de fixação dos parafusos pediculares nos corpos vertebrais ao variar a angulação durante o reposicionamento. Método: Neste estudo foram utilizados oito suínos, totalizando 40 vértebras lombares. As vértebras foram divididas em quatro grupos de estudo. No primeiro grupo os parafusos foram colocados a $0^{\circ}$; no segundo, introduzidos e recolocados na mesma posição $\left(0^{\circ}\right)$; no terceiro, houve uma variação da angulação de $14^{\circ}$ no reposicionamento e, no quarto, uma variação da angulação inicial de $28^{\circ}$. Todos os parafusos foram testados quanto à força de arrancamento. No resultado o grupo I apresentou uma média de arrancamento de $146,85 \mathrm{~N}$; o grupo II uma média de 77,34N; o grupo III, $97,75 \mathrm{~N}$ e o grupo IV teve uma média de $110,02 \mathrm{~N}$. Houve uma variação estatística significante na força de arrancamento. Conclusão: Com base nos resultados, conclui-se que o reposicionamento dos parafusos deve ser evitado devido à perda de força de fixação no corpo vertebral e, no caso de necessidade de recolocação, esta deve ser feita em angulações as mais diferentes possíveis da inicial.

Estudos do Grau de Informação dos Cardiologistas a Cidade de São Paulo - Brasil - Em Relação à Entidade de Baixa Prevalência à Morte Cardíaca Súbita: Síndrome de Brugada

Autor: Andrés Ricardo Péres Riera

Orientador: Prof. Dr. Celso Ferreira

Defesa: $11 / 12 / 2007$

Objetivo: Avaliar o grau de conhecimento dos cardiologistas atuantes na cidade de São Paulo, Brasil, em relação à entidade de baixa prevalência, associada à elevada taxa de morte súbita: a síndrome de Brugada. Métodos: Foram entrevistados 244 cardiologistas, $61,1 \%$ do sexo masculino, com idade média de 44,32 $\pm 10,83$ anos, submetidos a um instrumento constituído de duas partes. Na primeira, registramos gênero, idade e dados relacionados ao perfil acadêmico-profissional. Na segunda, respondida apenas pelos profissionais que manifestaram ter algum conhecimento da síndrome, avaliou - sem possibilidade de consulta - o grau de conhecimento sobre a entidade. Empregamos análise uni e multivariada sobre a percentagem média de acertos e erros e a influência do perfil acadêmico-profissional no desempenho. Resultados: Manifestaram ter algum conhecimento $98,8 \%$ dos entrevistados. O percentual de acertos foi de $45,7 \%$. Os que fizeram ou fazem residência em cardiologia mais de 2 anos, acertaram $30 \%$ a mais que aqueles sem residência $(\mathrm{p}<\mathrm{O}, 001)$. Os com pósgraduação acertaram em média $20 \%$ a mais que os não pósgraduados $(\mathrm{p}<0,001)$. Os com título de especialista acertaram em média $13 \%$ a mais que os não titulados $(\mathrm{p}=0,04)$. Quando vinculado à instituição de ensino, o percentual médio de acertos foi $14 \%$ superior $(\mathrm{p}<0,001)$ e se vinculado a SOBRAC, o aumento médio de acertos foi de $10 \%(\mathrm{p}=0,004)$. Conclusões: A residência em cardiologia foi o elemento do perfil acadêmico de maior significância para o aprendizado, seguindo-se do vínculo com instituições de ensino, SOBRAC e o título de especialista em cardiologia. O grau de conhecimento médico relativo às questões específicas foi satisfatório para quase a metade dos médicos da amostra estudada. Torna-se aparente a necessidade de maior e melhor conhecimento na formação geral e na especialidade, para o bom desempenho em áreas médicas específicas. 
Resultados Preliminares da Avaliação da Função Pulmonar de Obesos Mórbidos Submetidos à Fisioterapia Pré-Operatório de Gastroplastia

Autor: Beatriz Galuzzi Garcia Piva

Orientadora: Profa. Dra. Ethel Zimberg Chehter

Defesa: $14 / 12 / 2007$

Objetivo: Estudar a eficiência das técnicas fisioterapêuticas, padrões ventilatórios (PV), incentivador respiratório (IR), aplicados no pré-operatório de gastroplastia através da avaliação da função pulmonar. Método: Ralizado em obesos mórbidos submetidos à gastroplastia, divididos em dois grupos. Grupo I controle - 18 indivíduos, com orientações pré-operatórias (intubação orotraqueal, importância da fisioterapia, deambulação precoce e tosse). Grupo II - 13 indivíduos com fisioterapia pré-operatória (PV, IR, Reeducação diafragmática) 3x semana, 15 dias antes da cirurgia, por 40 minutos, e orientações pré-operatórias. Em ambos foram colhidos os dados: Plmáx, Pemáx, CVF, VEF1, FEF 2575\%, VEF1/CVF, PO2, PCO2, SATO2, FC, PAD, PAS, nas fases pré-fisioterapia (1), pré-operatória, pós-operatória (2) e pré-alta hospitalar (3). Resultados: Nos dados preliminares biodemográficos, de internação hospitalar e comorbidades associadas. Os grupos mostraram-se homogêneos. Para CVF, VEF1, VEF1/CVF, FEF2575\% houve diferença no grupo II e de CVF4, VEF1 4, VEF1/CVF 4 e FEF 2575\% 2 foram melhores no grupo I. Não houve diferença entre os grupos na força muscular (Pimáx e Pemáx) gasométricos (PO2, PCO2), hemodinâmicos (FC, PAS e PAD). Houve diferença em VC 3 e SATO2 3 os melhores resultados estão no grupo I. Conclusão: Conclui-se que a fisioterapia pré-operatório melhorou a CVF e VEF1, melhorando a restrição causada pela obesidade mórbida e, não trouxe benefícios nos outros dados colhidos, talvez pelo tempo insuficiente da fisioterapia pré-operatório ou da necessidade de outras técnicas, ou até mesmo pelos afeitos deletérios causados pela cirurgia abdominal alta.

\section{Evolução de Parâmetros Goniométricos em Mulheres Mastectomizadas Submetidas à Fisioterapia}

Autor: Isabelle Martins Squarcino

Orientadora: Profa. Dra. Monica Akemi Sato

Defesa: 23/01/2008

O objetivo deste estudo foi analisar a goniometria do ombro de pacientes submetidas à cirurgia para tratamento de câncer de mama antes e depois da realização de fisioterapia e seus efeitos em longo prazo. A goniometria do ombro ipsilateral à cirurgia para os movimentos de flexão e abdução foi realizada antes e após a fisioterapia em 20 pacientes. A comparação em relação ao ombro contralateral foi realizada em longo prazo, bem como foi feita a comparação com 23 mulheres que não realizaram fisioterapia (grupo controle). Observou-se aumento goniométrico significativo nos movimentos de abdução e flexão do ombro ipsilateral cirurgia após a realização da fisioterapia. Em relação ao membro contralateral, não houve diferença goniométrica significativa em ambos os grupos estudados. A fisioterapia abreviou a recuperação da amplitude de movimento de flexão e abdução do ombro ipsilateral à cirurgia e garantiu sua manutenção.

\section{Influência do Índice de Massa Corporal e Circunferência Abdominal na Pressão Arterial Sistêmica}

Autor: Marcelo Nunes Iampolsky

Orientadora: Profa. Dra. Roseli Oselka Saccardo Sarni

Defesa: $17 / 12 / 2007$

Objetivo: Avaliar os níveis pressóricos em crianças e adolescentes e relacioná-Ios com a presença de obesidade e com a circunferência abdominal. Método: Por meio de estudo prospectivo e transversal avaliou-se 1408 escolares, entre 5 e 10 anos e 11 meses, matriculados em escolas públicas do Município de Santo André. Dados obtidos: peso ao nascer; peso e estatura (expressos como escore $\mathrm{z}$ do índice de massa corpórea - ZIMC e estatura para a idade - ZE; CDC, 2000); circunferência abdominal (Freedman, 1999) e pressão arterial (Task Force, 2004), medida única e aferida pelo mesmo examinador. Análise estatística: Qui-quadrado e odds ratio. Resultados: A mediana de idade foi de 7,2 anos, sendo 50,6\% do sexo feminino. Níveis pressóricos elevados foram encontrados em $19,2 \%$ e 12,2\% dos escolares para pressão arterial sistólica e diastólica, respectivamente. Verificou-se: baixa estatura $(Z W<-2) 2,6 \%$, desnutrição (ZIMC < -2) 3,1\%, obesidade (ZIMC > 2) 7,3\% e aumento da circunferência abdominal (> p 90) 13,4\%. A presença de obesidade foi o fator mais fortemente associado ao aumento de pressão arterial sistólica $(\mathrm{OR}=2,1 ; \mathrm{p}<0,001)$ e diastólica $(\mathrm{OR}=2,6 ; \mathrm{p}<0,001)$, respectivamente. A circunferência abdominal também mostrou ser fator de risco importante para pressão arterial sistólica elevada $(\mathrm{OR}=1,6 ; \mathrm{P}=0,027)$. Conclusões: A pressão arterial sistêmica elevada em crianças e adolescentes associa-se com obesidade e aumento da circunferência abdominal sendo, portanto, importante seu diagnóstico precoce.

\section{Avaliação neurológica neonatal, pelo método Dubowitz de recém-nascidos pré-termo em idade de termo comparada a de recém-nascidos a termo}

Autor: Marina Ortega Golin

Orientadora: Profa. Dra. Roseli Oselka Saccardo Sarni

Defesa: 23/06/2008

Objetivo: comparar a avaliação neurológica neonatal de recém-nascidos pré-termo em idade de termo com a de recém-nascidos a termo. Em recém-nascidos pré-termo, relacionar as alterações da avaliação com características destes recém-nascidos e intercorrências. Método: Foi realizado estudo prospectivo avaliando, pelo Método Dubowitz, 60 recém-nascidos a termo e 30 recém-nascidos pré-termo do Hospital Estadual Mário Covas, Santo André. Os pontos de corte da pontuação total foram de 30,5 e 26 para comparação entre recém-nascidos pré-termo e recém-nascidos a termo e para análise do grupo de recém-nascidos pré-termo, respectivamente. Análise estatística: teste de Mann-Whitney, Qui-Quadrado. Resultados: Noventa por cento dos recém-nascidos pré-termo não atingiram a pontuação esperada para a idade de termo $(\mathrm{p}<0,0001)$, com alterações mais evidentes nas dimensões tônus, tipo de tônus e movimentos. Nos recém-nascidos pré-termo $56,7 \%$ não atingiram pontuação total superior a $26(\mathrm{p}<0.05)$. A sepse neonatal foi a única intercorrência associada de maneira significativa com pontuações abaixo da normalidade em recém-nascidos pré-termo $(\mathrm{p}=0,009)$. Conclusão: A elevada freqüência de alterações na avaliação neurológica observada sugere que o Método Dubowitz necessita adaptações para nossa população e estabelecimento de pontuação de corte específica para recém- nascidos pré-termo. 
A influência do Tabagismo atual nas Respostas Subjetivas e Fisiológicas à Reabilitação Pulmonar em Paciente com Doença Pulmonar Obstrutiva Crônica

Autor: Vivian Taciana Simioni Santana

Orientador: Prof. Dr. Elie Fiss

Defesa: 04/07/2008

Objetivo: Investigar a aderência e os impactos subjetivo e objetivo da reabilitação pulmona (RP) em pacientes tabagistas e ex-tabagistas portadores da doença pulmonar obstrutiva crônica (DPOC). Método: Em um estudo prospectivo, 18 pacientes ex-tabagistas e 23 tabagistas (GOLD estadios II-IV) foram incluídos num programa multidisciplinar de RP. Os pacientes foram submetidos à avaliação clínica e subjetiva (dispnéia e qualidade de vida). Em adição, foram realizadas avaliações da composição corporal, testes de função pulmonar e teste da caminhada de 6 minutos (TC6). Nos pacientes tabagistas, obteve-se o nível de dependência da nicotina pela escala de Fagerstrom. Resultados: Houve associação significante entre tabagismo atual e não aderência à RP (razão de chance $=2,9(1,6-4,1)$; P < $0.01)$. Não se observou diferença significante nas variáveis entre os pacientes tabagistas que finalizaram ou não à $\mathrm{RP}(\mathrm{p}>0,05)$. Os pacientes tabagistas que completaram o programa $(\mathrm{N}=$ 16) apresentaram melhora similar nas variáveis subjetivas e objetivas quando comparados aos pacientes ex-tabagistas. Adicionalmente, 3 pacientes interromperam o hábito tabágico e houve redução estatisticamente significante no número cigarros consumidos diariamente.e no grau de dependência à nicotina $(\mathrm{p}<0,05)$. Conclusão: Embora o tabagismo atual reduza a aderência à RP, pacientes tabagistas com DPOC que completam tais programas apresentam ganhos clínicos e funcionais equivalentes aos observados nos ex-tabagistas. A RP, mesmo sem um programa estruturado de cessação do tabagismo, pode associar-se com redução, ao menos à curto prazo, na dependência à nicotina.

\section{Uso do Tabaco entre Adolescente Escolares do Município de Santo André e Fatores de Risco Associados}

Autor: Halley Ferraro Oliveira

Orientadores: Prof. Dr. Marco Akerman e Profa. Dra. Lígia de Fátima Nóbrega Reato Defesa: 06/08/2008

Objetivo: Verificar o início do uso do fumo e fatores associados ao tabagismo entre estudantes do ensino médio do município de Santo André em 2005. Método: Estudo transversal com questionário padronizado, auto-aplicável e anônimo, aplicado em adolescentes escolares, de ambos os sexos, matriculados no primeiro ano do ensino médio de duas escolas de Santo André Levantadas as seguintes variáveis: idade, sexo, etnia, prática de esportes, religião, hábitos do adolescente/familiar. Para verificar a associação entre classe sócio-econômica e as variáveis qualitativas e comparação entre experimentadores e não experimentadores foi utilizado o teste de Qui quadrado. O nível de significância adotado foi de 5\%. Pacote estatístico utilizado SPSS 16.0 for Windows. Resultados: Dos 226 questionários aplicados, 54 (24\%) respondidos por adolescentes experimentadores e $172(76 \%)$ por não experimentadores. $10(19 \%)$ experimentadores na escola particular reprovaram, contra $14(8 \%)$ não experimentadores. $14(26 \%)$ experimentadores não possuem religião, contra 31 (18\%) não experimentadores. Não ouve consumo de bebida alcoólica na última semana e aqueles que beberam, eram experimentadores de cigarro. A maioria dos experimentadores conhecia usuários de drogas ilícitas. Os pais, irmãos mais velhos fumantes e os cinco melhores amigos representam uma associação para a experimentação do fumo. Conclusão: Há uma associação significativa entre o uso do fumo e: sexo feminino, reprovação escolar, o uso de bebidas alcoólicas e ou substâncias psicotrópicas, pais/irmãos mais velhos fumantes, cinco melhores amigos ou namorado (a) fumantes e contato com a fumaça. No presente estudo a média etária foi de 11,6 anos para o início do hábito tabagista, coincidindo com o trabalho do CEBRID, conforme apresentado neste estudo. Não houve associação significativa entre o uso do fumo com a mãe fumante, atnia (raça) e a religião. Com relação ao esporte praticado fora da aula, os experimentadores praticavam menos que os não experimentadores, porém neste trabalho não se observou uma diferença estatisticamente significativa.

\section{Estudo Comparativo da Influência de Dois Contraceptivos Hormonais Orais Combinados Contendo Diferentes Doses de Etinil Estradiol e Levonorgestrel sobre a Androgênicidade Plasmática}

Autor: Rodolfo Strufaldi

Orientadores: Prof. Dr. César Eduardo Fernandes e Prof. Dr. Luciano de Melo Pompei Defesa: 06/08/2008

Objetivo: Comparar os efeitos de duas formulações de anticoncepcionais hormonais orais contendo diferentes doses de etinilestradiol (EE) e levonorgestrel (LNG) sobre a androgênicidade plasmática e a função sexual feminina. Método: Estudo prospectivo, aberto, aleatorizado conduzido no Centro de Planejamento Familiar da Faculdade de Medicina do ABC, avaliou 101 mulheres sem queixas de disfunção sexual, com média etária de 27,8 anos, as quais foram divididas em dois grupos: EE30/ LNG150 (n=51), utilizando EE 30mcg/dia e LNG 150mcg/dia e Grupo EE20/LNG100 ( $\mathrm{n}=50$ ) com EE $20 \mathrm{mcg} /$ dia e LNG $100 \mathrm{mcg} /$ dia. A medicação contraceptiva foi administrada em ciclos de 21 dias, com pausas de sete dias, durante seis ciclos consecutivos. A função sexual foi avaliada no início e ao final de seis meses do período de observação por meio de questionário para avaliação do índice de função sexual (FSFI). Nos mesmos momentos foram realizadas dosagens de Testosterona Total (TT), Testosterona livre (TL), e da globulina ligadora de hormônios sexuais (SHBG) e foi calculado o índice de androgênio livre (IAL). Resultados: Ambos os grupos apresentaram redução estatisticamente significante de TT e IAL ao final do estudo, sendo que as concentrações séricas foram estatisticamente menores no grupo que recebeu anticoncepcional hormonal contendo $30 \mathrm{mcg}$ de EE. A redução percentual média de TT no grupo EE30/LNG150 foi de 40\% e de 20,6\% no grupo EE20/ LNG100 ( $\mathrm{p}=0,008$ ) e a do IAL foi de 57,7\% no grupo EE30/LNG150 e 38,9\% no EE20/LNG100 $(\mathrm{p}=0,002)$. Os níveis da SHBG aumentaram em ambos os grupos ao longo do tempo, sendo maior no grupo quê recebeu anticoncepcional de $30 \mathrm{mcg}$ de EE, com significância estatística. Os aumentos médios percentuais da SHBG foram de 31,7\% no grupo EE30/LNG150 e de 21,9\% no EE20/LNG100 $(\mathrm{p}=0,078)$. Quanto à avaliação sexual, ambos os grupos estudados mostraram melhora estatisticamente significativa no escore total e nos domínios desejo, orgasmo e satisfação do FSFI durante o período de observação, não havendo diferença estatística entre os grupos. No domínio excitação, embora tenh havido melhora do escore nos dois grupos, o mesmo foi significativo apenas no grupo EE30/LNG150. Quando se avaliou a associação do IAL e os escores parciais e total dos domínios do FSFI, observou-se significância estatística apenas no desejo e no escore total, com fraca correlação nos dois grupos por meio do teste de regressão múltipla. Conclusão: Houve melhora da função sexual feminina com as duas formulações contraceptivas empregadas. Não houve correlação entre os escores da escala da função sexual e a diminuição dos níveis de TT e IAL com o uso de ambos contraceptivos.

\section{Estudo Comparativo dos Efeitos da Descontinuação Brusca e Progressiva da Terapêutica Hormonal sobre a Sintomatologia Vasomotora em Mulheres Climatéricas}

Autor: Everaldo Porto Cunha

Orientador: Prof. Dr. César Eduardo Fernandes

Defesa: $10 / 11 / 2008$

A TH é indiscutivelmente a melhor opcão de tratamento dos sintomas climatéricos, porém, por várias razões, algumas mulheres optam por sua descontinuação. O objetivo deste estudo foi comparar os efeitos da descontinuação brusca e da descontinuação progressiva, com redução da dose hormonal da TH, sobre os sintomas climatéricos. Foram incluídas neste estudo 60 mulheres menopausadas usuárias de TH na dose plena, e divididas em três grupos de 20, assim distribuídas: grupo I medicado com placebo durante 6 meses, grupo II medicado com TH baixa dose (17 B estradiol $1,0 \mathrm{mg}+$ acetato de noretisterona $0,5 \mathrm{mg}$ ) por 2 meses, seguidos de placebo por 4 meses, e o grupo III, medicado com TH baixa dose por 4 meses, seguidos de placebo por 2 meses. Os grupos foram avaliados bimestralmente, por um período de 6 meses, e os sintomas climatéricos foram quantificados através do Índice Menopausal de Blatt e Kupperman no seu escore total e dos fogachos. Os resultados mostraram que não há diferença estatística significante quando se faz a comparação inter-grupos do IMBK, e dos fogachos isoladamente, no momento da inclusão e aos 6 meses, quando todos os grupos se encontram fazendo uso respectivamente de TH dose plena e de placebo. Nas avaliações intermediárias, aos 2 e 4 meses, os grupos mostraram comportamento distinto quando comparados o IMBK total e os fogachos isoladamente. Na avaliação do IMBK total não se observou em nenhum dos tempos do estudo, diferença estatística significante na comparação entre os grupos placebo e baixa dose, porém quando comparados em relação à variável fogacho isoladamente, nota-se diferença estatística muito significante entre as usuárias de droga ativa e usuárias de placebo. Estes resultados nos permitem concluir que o retorno da sintomatologia climatérica, particularmente os fogachos, independe da maneira escolhida para a interrupção da TH. 
Estudo Comparativo entre as Anastomoses Cervicais Esofagogástricas com Invaginação do Coto Esofágico no Interior do Estômago, após Esofagectomia por Carcinoma do Esôfago

Autor: Alexandre Cruz Henriques

Orientador: Prof. Dr. Jaques Waisberg

Defesa: $12 / 11 / 2008$

Objetivo: Avaliar a incidência de fístula e estenose da anastomose esofagogástrica cervical com invaginação do coto esofágico no interior do estômago na esofagectomia para tratamento do carcinoma do esôfago. Método: Foram estudados dois grupos de doentes com carcinoma do esôfago torácico ou abdominal submetidos à esofagectomia subtotal e esofagogastroplastia. O grupo I (estudo) foi constituído por 29 doentes, no qual foi realizada a anastomose esofagogástrica com invaginação de segmento do coto esofágico no interior do estômago, e o grupo II (controle) foi constituído por 36 doentes submetidos à anastomose esfagogástrica término-terminal sem invaginação. Resultados: No grupo I, 3 (10,3\%) doentes apresentaram fístula da anastomose esofagogástrica com repercussão clínica mínima. No grupo II observouse fístula com franca saída de saliva em $11(30,5 \%)$ doentes. A frequencia de fístula nos doente do grupo I foi significantemente menor $(\mathrm{p}=0,04)$ do que nos do grupo II. No grupo I, estenose fibrótica da anastomose ocorreu em $7(24,1 \%)$ enfermos, ao passo que no grupo II 10 $(27,7 \%)$ enfermos evoluíram com estenose, não se constatando diferença significante $(\mathrm{p}=0,72)$ entre esses grupos. Conclusão: No tratamento do carcinoma do esôfago, a esofagectomia com anastomose esofagogástrica cervical com invaginação do coto esofágico no interior do estômago determina menor ocorrência de fístula esofagogástrica quando comparado à anastomose sem invaginação. A incidência de estenose da anastomose esofagogástrica não difere qualquer que seja a técnica utilizada.

\section{Estudo Comparativo entre o Exame Físico e o Mapeamento Duplex na Exploração Cirúrgica da Recidiva de Varizes de Membros Inferiores a Partir da Junção Safeno-Femoral}

Autor: Gilberto Narchi Rabahie

Orientador: Prof. Dr. Jaques Waisberg

Defesa: 25/11/2008

Introdução: A recidiva de varizes em membros inferiores é complicação freqüente da safenectomia. Sua incidência varia entre $7 \%$ a $80 \%$ dos casos operados. Na avaliação préoperatória o mapeamento duplex é considerado método confiável para se determinar necessidade ou não da reabordagem da crossa da veia safena interna na reoperação. Objetivo: Avaliar a acurácia do exame físico e do mapeamento duplex no diagnóstico da recidiva de varizes na região da crossa da veia safena interna, em doentes previamente safenectomizados, comparando-os com os achados da exploração operatória da junção safeno-femoral. Método: Foram estudados prospectivamente 30 doentes envolvendo 37 membros submetidos previamente à safenectomia interna para tratamento de varizes que foram reoperados por recorrência de varizes na região inguinal ou em face ântero-superior da coxa. Todos os doentes foram submetidos ao exame físico e ao mapeamento duplex tendo os dados confrontados com os achados da exploração cirúrgica da junção safeno-femoral na reoperação. Resultados: A concordância diagnóstica entre o exame físico e o mapeamento duplex ocorreu em 26 (70,3\%) membros e esteve ausente em outros $11(29,7 \%)$ membros $(p>0,05)$. Nos membros com ausência de concordância, quatro apresentaram crossa da veia safena interna intacta e nos outros sete membros havia presença de coto de veia safena interna insuficiente. Conclusão: Neste estudo concluise que no doente já submetido à safenectomia interna, o achado do exame físico de varizes recidivadas em região inguinal e na face antero-superior da coxa é suficiente para indicar a re-exploração cirúrgica da crossa da veia safena interna. O mapeamento duplex realizado sem padronização adequada conduz a incidência elevada de resultados falsonegativos. Na recorrência de varizes em face antero-medial da coxa, sua causa mais freqüente é o tratamento inadequado da crossa da veia safena interna, no nível da junção safeno femoral.
Análise Comparativa das Técnicas Cirúrgicas de "Slings" Transobturatório Sintético e Aponeurótico Retropúbico para a Correção da Incontinência Urinária de Esforço

Autor: Marcos Tcherniakovsky

Orientadores: Prof. Dr. Eric Roger Wroclawski e Prof. Dr. César Eduardo Fernandes Defesa: 17/11/2008

Objetivo: Analisar comparativamente a eficácia e a segurança de duas diferentes técnicas cirúrgicas, "slings" transobturatório sintético e aponeurótico retropúbico, no tratamento da incontinência urinaria aos esforços (IUE) em mulheres. Método: As pacientes foram aleatoriamente separadas em dois grupos para fins de aplicação de cada uma das técnicas cirúrgicas. Um dos grupos com 21 pacientes, com media etária de 47 anos (31-71), foi submetido a correção cirúrgica pela técnica de "sling" transobturatório com tela sintética, enquanto no outro, as 20 pacientes, média de idade 52 anos (31-71), foram operadas pela técnica de "sling" retropúbico com tela natural aponeurótica. Todas as pacientes foram submetidas a exame físico completo e teste urodinâmico com verificação de perda urinaria aos esforços. A pressão de perda aos esforços á manobra de Valsava (VLPP) foi avaliada aos $200 \mathrm{~mL}$ de repleção vesical. Foi utilizada a classificação de quantificação do prolapso dos órgãos pélvicos (POP-Q) em todas as pacientes para o diagnóstico de outras distopias concomitantes do compartimento pélvico anterior, posterior e apical. Resultados: A duração do procedimento foi de 12,8 $\pm 2,4$ minutos no grupo operado por via transobturatória, sendo significativamente menor que a das pacientes submetidas à via retropúbica que foi de 59,7+10,3 minutos. A alta hospitalar ocorreu após micção espontânea em $90,5 \%$ e $85 \%$, respectivamente, em cada um dos grupos. A sondagem vesical intermitente se fez necessária em $9,5 \%$ das pacientes do primeiro grupo e em $15 \%$ das pacientes do segundo grupo. O índice de cura foi de $90,5 \%(19 / 20)$, respectivamente, nas pacientes operadas pela via transobturatória e retropúbica. O grupo operado pela via transobturatória apresentou menor índice de complicações em comparação ao submetido à cirurgia por via retropúbica. Conclusão: As técnicas de "sling" transobturatório sintético e de "sling" aponeurótico retropúbico foram igualmente eficazes para tratamento de incontinência urinaria aos esforços. A técnica de "sling" transobturatório apresentou menos complicações pós-operatórias e menor tempo cirúrgico que a técnica de "sling" aponeurótico retropúbico.

\section{Contribuição da Tomografia Computadorizada Helicoidal Abdominal no Estadiamento Pré-Operatório do Carcinoma Gástrico}

Autor: Flavio Mendes de Oliveira

Orientador: Prof. Dr. Jaques Waisberg

Defesa: 04/12/2008

Objetivo: Analisar a sensibilidade da tomografia helicoidal abdominal da detecção do comprometimento linfonodal e de metástases hepáticas e peritoneais no pré-operatório do carcinoma gástrico. Método: Estudou-se 52 doentes operados por carcinoma gástrico e estadiados por tomografia helicoidal abdominal com contrates oral e intravenoso. Esses resultados foram correlacionados com os achados intra-operatórios e exame anatomopatológicos dos espécimes cirúrgicos. Resultados: A neoplasia gástrica localizou-se na região do antropilórica em $38(73,1 \%)$ doentes, na cárdia em $8(15,4 \%)$ e no corpo e fundo em $6(11,5 \%)$. Treze $(25,0 \%)$ doentes apresentavam carcinomatose peritoneal. A tomografia helicoidal abdominal detectou lesão gástrica em $25(48,1 \%)$ doentes, metástases hepáticas em $6(11,5 \%)$, acontecimento de linfonodos em $5(9,6 \%)$, ascite em 4 (7,7\%) e comprometimento no fígado, baço e pâncreas em $1(1,9 \%)$. Na laparotomia constatou-se metástase hepáticas em $6(11,5 \%)$ doentes e ascite em $12(23,1 \%)$. Nos doentes submetidos à ressecção com intenção curativa da neoplasia foram identificados pela tomografia helicoidal abdominal préoperatória $27(67,5 \%)$ doentes dom linfonodos sugestivos de comprometimento. O exame anatomopatológico mostrou $16(40,0 \%)$ doentes com linfonodos infiltrados pelo carcinoma gástrico. A sensibilidade do exame de tomografia helicoidal abdominal na identificação préoperatória da lesão gástrica foi $48,1 \%$, de linfonodos acometidos foi $18,5 \%$ e para metástases hepáticas foi $100 \%$. Treze $(25 \%)$ doentes apresentaram metástases peritoneais não constatadas pela tomografia helicoidal. Conclusão: $O$ exame de tomografia computadorizada helicoidal abdominal no pré-operatório do carcinoma gástrico apresentou sensibilidade elevada na detecção de metástases hepáticas, sensibilidade baixa na deteç̧ão do comprometimento linfonodal pela neoplasia e não foi identificado metástases peritoneais. 
Níveis Séricos Pré-Operatórios e Imunoexpressão Tecidual do Marcador Tumoral CA 242 no Carcinoma Colorretal: Relação com os Aspectos Anatomológicos da Neoplasia

Autor: Frederico Rezende Ghersel

Orientador: Prof. Dr. Jaques Waisberg

Defesa: 11/12/2008

Objetivo: Comparar os níveis séricos pré-operatórios e a imunoexpressão tecidual do CA 242 em doentes operados de carcinoma colorretal, relacionando-os com os aspectos morfológicos da neoplasia. Método: 29 doentes com carcinoma colorretal foram operados com intenção curativa. $16(55,1 \%)$ eram homens e $13(44,8 \%)$ mulheres, com média de idade de 69,2 anos. O nível sérico do CA 242 foi determinado pelo método ELISA e a imunoexpressão por imunoistoquímica com anticorpo monoclonal anti-CA 242. O nível sérico e a imunoexpressão do CA 242 foram relacionados com variáveis morfológicas. Foram utilizados testes paramétricos e não paramétricos, fixando-se em $5 \%$ o nível para a rejeição da hipótese de nulidade. Resultados: A relação entre o nível sérico e a imunoexpressão do CA 242 não apresentou diferença significante $(\mathrm{p}=0,76)$. $\mathrm{O}$ nível sérico $(\mathrm{p}=0,54)$ e a imunoexpressão $(\mathrm{p}=0,63)$ do CA 242 não apresentaram relação significante com o tamanho da neoplasia, invasão vascular sanguínea $(\mathrm{p}=0,09)$ ou linfática $(\mathrm{p}=0,09)$ e com nível de infiltração do carcinoma na parede intestinal $(\mathrm{p}=0,56)$. Houve relação significante $(\mathrm{p}=0,02)$ entre o nível sérico de CA 242 e a presença de acometimento linfonodal. Conclusão: Não há relação entre a imunoexpressão do CA 242 com o nível sérico do marcador nem com os aspectos morfológicos do carcinoma colorretal. O nível elevado do CA 242 apresentou relação significante com o comprometimento linfonodal pelo carcinoma colorretal.

\section{Complicações em Cirurgia Dermatológica: Proposta de uma Estratégia para a abordagem e prevenção de intercorrências clínicas}

Autor: Fabio Roismann Timoner

Orientador: Prof. Dr. Carlos d'Apparecida Santos Machado Filho Defesa: 19/12/2008

Durante as ultimas décadas houve um crescimento progressivo da complexidade dos procedimentos em cirurgia dermatológica, o que levou a um aumento potencial dos seus riscos para complicações, tanto clínicas como cirúrgicas. Entretanto existem, poucos relatos na literatura que sugiram estratégias para abordá-las. Este estudo propõe uma estratégia que seja efetiva para a abordagem e prevenção das complicações clínicas em cirurgia dermatológica. Foi elaborado um fluxograma para indicar que tipo de suporte (Suporte Básico de Vida - SBV ou Suporte Avançado de Vida em Cardiologia - SAVC) deve ser utilizado em cada cirurgia considerando (a) o estado físico do paciente, segundo a classificação da American Society of Anesthesiologists (ASA); (b) o grau de sedação e (c) o porte do procedimento realizado (as cirurgias dermatológicas foram classificadas em "Porte Pequeno" e "Porte Médio"). Estes três itens foram denominados "tríade decisória". De acordo com este fluxograma, pacientes e cirurgias de "Porte Pequeno" e ASA $\leq 2$ devem receber SBV; "Porte Pequeno" e ASA $>2$, SAVC. Pacientes em cirurgias de "Porte Médio" ou sedação profunda devem receber SAVC. Pela adequação de suporte básico ou avançado em cardiologia, de acordo com o grau de risco de cada procedimento, determinado através da tríade decisória pelo fluxograma, a estratégia proposta pode ser de extrema valia na abordagem e prevenção de intercorrências clínicas em cirurgia dermatológica.

\section{Prevalência de Staphylococcus aureus em Profissionais} da Saúde de um Hospital de Ensino de Santo André - SP

Autor: Milton Jorge de Carvalho

Orientador: Prof. Dr. Caio Parente Barbosa

Defesa: $2 / 12 / 2008$

Introdução: A crescente prevalência de Staphylcoccus aureus meticilina resistente (MRSA) é uma preocupação mundial. Os profissionais da área da saúde atuam como importante disseminador, podendo ser carreadores transitórios. Objetivo: Analisar a prevalência de Staphylcoccus aureus na saliva de profissionais da área da saúde, de um hospital de ensino estadual de grande porte. Método: Estudo de corte transversal realizado em um hospital público de grande porte, do município de Santo André-SP, de 2006 a 2008, com a aplicação de um questionário aos sujeitos e coleta de material (saliva) em três momentos distintos. De 340 participantes, 22 eram médicos ginecologistas e obstetras, 42 enfermeiros, 99 técnicos de enfermagem, 177 auxiliares de enfermagem. O projeto foi aprovado pelo Comitê de Ética e Pesquisa da Faculdade de Medicina do ASC. Após o isolamento e identificação dos Staphylcoccus aureus procedeu-se às provas de suscetibilidade antimicrobiana. Os dados foram processados no Statistical Package Social Science (SPSS), versão 15.0 for Windows. Resultados: De 340 profissionais que coletaram três amostras de saliva, 162 estavam colonizados. Assim, a prevalência de Staphylcoccus aureu foi de 47,6\% (162/340), sendo 43,5\% de Staphylcoccus aureus sensíveis à meticilina. Por meio do método

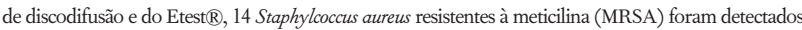
(prevalência $=4,1 \%$ ), sendo 9 em auxiliares de enfermagem e 5 em técnicos de enfermagem. Um total de 11 do sexo feminino e a maioria (42,9\%) com idade entre 19 e 29 anos. Quanto ao setor de trabalho, 04 trabalhavam na clínica cirúrgica, 04 na clínica e centro obstétrico, 02 no berçário e UTI neonatal, 02 na UTI, 01 no centro cirúrgico e recuperação pós anestésica e 01 na UTI pediátrica e coronariana. A prevalência de MRSA foi de 4,1\% (14/340). Os MRSA isolados apresentaram 100\% de resistência oxacilina; $92,8 \%$ à eritromicina, $57,1 \%$ à clindamicina, $57,1 \%$ à cefoxitina, $42,8 \%$ à ciprofloxacina, $7,1 \%$ à gentamicina e $7,1 \%$ à sulfametoxazol-trimetoprima. Todos apresentaram sensibilidade à tetraciclina, rifampicina, vancomicina, Iinezolida e mupirocina. Conclusão: A prevalência de Staphylococcus aureus em profissionais da saúde, no presente estudo, foi de 47,6\%, (MSSA= 43,5\% e MRSA = 4,1\%). Avaliar a prevalência de MRSA entre profissionais da área da saúde é de extrema relevância por ser uma das medidas preventivas de infecção hospitalar. Deve-se investir tanto em prevenção como controle, merecendo destaque a valorização das precauções-padrão e de contato, as quais podem contribuir para controlar e ou minimizar as taxas de prevalência deste microrganismo. Discussão: As prevalências variaram segundo categoria profissional, setor de atuação e níveis de adesão às precauções específicas para microrganismos multi-resistentes, além de fatores intrínsecos do indivíduo. O perfil de resistência encontrado é indicativo de resistência aos macrolídeos, lincosaminas e estreptograminas, antimicrobianos amplamente empregados no tratamento de infecções estafilocócicas.

\section{Correlação entre Gasometria e Extubação de Indivíduos Criticamente Enfermos}

Autor: Hellen Magela Moreira Oliveira

Orientador: Prof. Dr. Neif Murad

Defesa: 23/01/2009

Introdução: O desmame ventilatório e extubação consiste em um ritual seguido nas unidades de terapia intensiva. Entretanto, muito se discute sobre a necessidade da obtenção de marcadores funcionais fidedignos para maior obtenção de sucesso desta etapa terapêutica. Tais marcadores têm a finalidade de prover este procedimento terapêutico com maior probabilidade de sucesso, consistindo em menor número de vezes de reintubação destes doentes críticos e ainda de prover meios para a tomada de decisão no momento crítico da extubação, haja vista que o tempo prolongado de ventilação mecânica corrobora para transtornos hemodinâmicos locais e sistêmicos. Mesmo os protocolos que concluíram com êxito este processo de extubação, ainda apresentam controvérsias, não existindo consenso ao respeito. Valores determinados de gasometria arterial são utilizados nas unidades de terapia intensiva como parâmetro preditor de sucesso, porém alguns trabalhos têm questionado esta conduta. Objetivo: Verificar se os valores da gasometria arterial $\left(\mathrm{pH}, \mathrm{PaO}_{2}, \mathrm{PaCO}_{2}\right)$ são marcadores para a tomada de decisão de extubação e se há correlação entre esses valores da gasometria com o resultado da extubação. Método: Realizou-se em estudo clínico prospectivo, transversal, com abordagem predominantemente quantitativa baseado em dados coletados dos pacientes internados na Unidade de Terapia Intensiva do Centro Hospitalar de Santo André. A casuística constou de 50 pacientes sob ventilação mecânica e intubados via orotraqueal, dos quais foram coletadas informações demográficas diagnóstico de admissão e motivo de intubação, dados gasométricos e nível sérico de hemoglobina além da aplicação de questionário ao profissional médico e ou fisioterapeuta com a finalidade de quantificar as tomadas de decisão de extubação baseadas nos dados gasométricos. Resultados: A gasometria influenciou a maioria das decisões, principalmente o profissional fisioterapeuta, em relação ao profissional médico. Entretanto, ao analisar a correlação entre os dados gasométricos e o sucesso de extubação não fo observado diferença estatisticamente significante. Conclusão: $O$ estudo mostra que a decisão de extubação ainda depende da análise gasométrica pelo profissional, porém os valores dos parâmetros gasométricos não apresentaram impacto na taxa de sucesso de extubação. 
0 Rodízio Precoce de Morfina para Metadona não é Implementado pelo Paracetamol na Analgesia de Pacientes Oncológicos: Estudo Prospectivo, Randomizado, Duplo Cego, Placebo Controlado

Autor: Daniel de Iracema Gomes Cubero

Orientador: Prof. Dr. Auro Del Giglio

Defesa: $11 / 03 / 2009$

Objetivo: Avaliar a eficácia da metadona em substituição à morfina, bem como verificar se acréscimo de paracetamol poderia reduzir o tempo para se atingir uma dose equianalgésica de metadona e melhorar a analgesia de pacientes oncológicos. Método: Cinqüenta pacientes consecutivos em uso regular de morfina, com dose estável há pelo menos 1 semana, foram submetidos à troca abrupta deste opióide por metadona e randomizados de forma duplo cega para receber paracetamol ( $750 \mathrm{mg}$ VO 6/6 horas) ou placebo por um período de 7 dias. Foram coletados dados referentes ao nível de dor, efeitos colaterais e aplicado o questionário de qualidade de vida QLQ-C30. Resultados: A substituição de morfina por metadona resultou na melhor do perfil de toxicidade, com redução da obstipação $(p<0,001)$ e da xerostomia ( $p$ $=0,003)$. Houve melhora da dor na Escala Visual Numérica $(\mathrm{p}=0,03)$, bem como melhor significativa do Nível Funcional e da Sintomatologia segundo o questionário QLQ-C30 ( $\mathrm{p}$ $=0,011 \mathrm{e} \mathrm{p}<0,001$ respectivamente).O acréscimo de paracetamol não refletiu melhora da analgesia, tampouco redução no tempo para estabilização das doses de metadona. Ao término do estudo, a maioria dos pacientes $(70,8 \% \mathrm{p}<0,001)$ preferiu prosseguir com metadona voltar para a morfina. Conclusão: A substituição precoce da morfina pela metadona mostrouse segura eficaz na redução de efeitos colaterais, com melhora na analgesia, permitindo posologia confortável a um custo inferior. Neste cenário a associação de paracetamol não refletiu melhora na analgesia ou redução no tempo para equianalgesia.

\section{Percepção dos Professores da Rede Regular de Ensino Sobre os Problemas Visuais e a Inclusão de Alunos com Baixa Visão}

Autor: Aparecida Tapia Maruyama

Orientador: Prof. Dr. José Ricardo Lima Rehder

Defesa: 18/03/2009

O objetivo deste estudo foi verificar e analisar o conhecimento a respeito dos problemas visuais e do tema baixa visão entre os professores da rede regular de ensino, justificando a importância do pedagogo especializado como elo de ligação entre o médico oftalmologista e a escola. O tipo de estudo foi survey descritivo e documental, com aplicação de um questionário a 230 professores que atuam na rede regular de ensino, de primeira a quarta série do Ensino Fundamental I da cidade de Santo André (SP). Os resultados mais relevantes foram: 123 $(53,5 \%)$ questionários respondidos. Quando perguntados se tinham recebido alguma orientação técnica a respeito de como lidar com alunos com baixa visão $21,1 \%$ respondeu afirmativamente, $95,9 \%$ acredita que o aluno com baixa visão tem dificuldades para aprender e 43,9\% não sabe como encaminhar a serviço oftalmológico especializado. A conclusão da pesquisa mostra que a falta de conhecimentos técnicos a respeito de como atuar diante do aluno com baixa visão justifica a importância do pedagogo especializado em baixa visão e cegueira (Visopedagogo), como elemento imprescindível para a educação inclusiva, na equipe multidisciplinar do médico Oftalmologista.

\section{Características e Percepções de Pais de Lactentes Portadores de Baixa Visão em Serviço Universitário de Reabilitação Visual}

Autor: Fabiana Maria Gomes Lamas

Orientador: Prof. Dr. José Ricardo Lima Rehder

Defesa: 18/03/2009

Objetivo: Este estudo surgiu da necessidade de compreendermos a perspectiva dos pai acerca do conceito da deficiência visual e da inclusão familiar para através desta compreensão podermos nos dedicar ao estudo do financiamento do sistema de saúde pública e sistemas de apuração de custos de clínicas oftalmológicas, planejando e viabilizando medidas econômicas que gerem ações preventivas e assistenciais adequadas a essa população. Método: Survey elaborado a partir de questionário auto-aplicável a 20 pais de crianças com idade entre 0 e 36 meses portadoras de baixa visão atendidas no setor de Visão Subnormal da Disciplina de Oftalmologia da Faculdade de Medicina do ABC. Resultados: A falta de assistência, a forma como o médico transmite as informações, a quase inexistência de profissionais habilitados a ensinar aos pais como trabalhar e assistir o deficiente, bem como o medo da discriminação, mostraram ser o maior problema informado pelos pais em relação a estas crianças. Conclusão: Programas de formação e de custeio de equipes multidisciplinares no atendimento aos pais e às crianças portadoras de deficiências devem ser incentivados.

\section{Ações do Peróxido de Hidrogênio, Pró-Oxidantes e Antioxidantes no Controle Barorreflexo em Ratos}

Autor: Marcelo Franchini Giusti

Orientador: Prof. Dr. Eduardo Colombari

Defesa: 25/03/2009

Introdução: As espécies reativas de oxigênio (ROS) têm demonstrado um papel importante em áreas relacionadas com o controle neural cardiovascular da pressão arterial. O objetivo deste estudo foi investigar os efeitos no $4^{\circ}$ ventrículo cerebral $\left(4^{\circ} \mathrm{V}\right)$ do peróxido de hidrogênio (H 2O2) e dos antioxidantes ácido ascórbico (AAC) e N-acetilcisteína (NAC) e pró-oxidante 3-amino-1,2,4-triazole (ATZ) sobre barorreflexo. O pró-oxidante ATZ também foi testado por via intravenosa (i.v.). Método: Ratos Wistar machos tiveram uma cânula-guia de aço inoxidável implantada no $4^{\circ} \mathrm{V}$. 24 horas antes dos experimentos, a artéria e veia femorais foram canuladas para mensuração de pressão arterial pulsátil (PAP) e administração de drogas, respectivamente. Após registros basais de PAM e FC, o barorreflexo foi testado com uma dose pressora de fenilefrina (PHE, $3 \mathrm{ug} / \mathrm{Kg}$, i.v.) e depressora de nitroprussiato de sódio (SNP, $30 \mathrm{ug} / \mathrm{Kg}$, i.v) antes (controle) e 5, 15, 30 e 60 minutos após a injeção de H2O2, ou AAC, ou NAC, ou ATZ ou no $4^{\circ} \mathrm{V}$. O ATZ também foi injetado por via intravenosa $(0.33 \mathrm{~g} / \mathrm{Kg})$ e o barorreflexo testado com PHE e SNP após 30 e 60 minutos. Resultados: A injeção de PHE produzido uma abolição da bradicardia reflexa determinada pela PHE aos $5(40+23 \mathrm{bpm})$, $15(26+22 \mathrm{bpm})$ e 30 minutos $(59+21 \mathrm{bpm})$ após a infusão de AAC no $4^{\circ} \mathrm{V}$ comparado aos níveis basais $(-93+13 \mathrm{bpm})$. Houve uma queda significativa da taquicardia suscita pelo teste com SNP aos 60 minutos $(72+23 \mathrm{bpm})$ após o controle $(151+23 \mathrm{bpm})$. No grupo tratado com NAC, a PHE induziu uma redução na bradicardia reflexa a 5 minutos $(-11+17 \mathrm{bpm})$ quando comparado ao controle $(-83+15 \mathrm{bpm})$. A taquicardia produzida pelo efeito depressor do SNP sobre a pressão arterial foi significativamente diminuída aos 30 minutos $(449,8+6,4)$ após a injeção central de ATZ, comparados ao controle $(480,3+9,2)$. O tratamento com ATZ intravenoso levou a uma diminuição significativa da PAM aos $30(30+3 \mathrm{mmHg})$ e 60 minutos $(26+5 \mathrm{mmHg})$ e $\mathrm{FC}$ aos $30(-36+3 \mathrm{bpm})$ e 60 minutos $(21+7 \mathrm{bpm})$ nas respostas induzidas pela PHE quando comparadas ao controle de PAM $(44+3 \mathrm{mmHg})$ e FC $(-58+10 \mathrm{bpm})$. A bradicardia reflexa determinada pela PHE foi atenuada aos $5(-27+9 \mathrm{bpm}), 15(-27+5 \mathrm{bpm})$ e $30(-35+13 \mathrm{bpm})$ minutos após o $\mathrm{H} 2 \mathrm{O} 2$ no $4^{\circ} \mathrm{V}$ comparado ao controle $(-101+23 \mathrm{bpm})$. Mudanças na PAM foram reduzidas aos $30(29+4 \mathrm{mmHg})$ e 60 minutos $(29+5 \mathrm{mmHg})$ após $\mathrm{H} 2 \mathrm{O} 2$ comparado ao controle $(42+4 \mathrm{mmHg})$. Não foram observadas mudanças significativas na taquicardia reflexa evocados pelo SNP após $\mathrm{H} 2 \mathrm{O} 2$ no $4^{\circ} \mathrm{V}$ comparado ao controle $(128+$ 31 bpm). Conclusão: Os scavengers AAC e NAC e o pró-oxidante ATZ agem no sistema nervoso central alterando os componentes autônomos do barorreflexo. 
Epidemiologia dos Traumatismos Craniofaciais no Centro Hospitalar de Santo André (Brasil) no Ano de 1999, na Vigência do Novo Código de Trânsito

Autor: Carlos Aurélio Andreucci

Orientadora: Profa. Dra. Lourdes Conceição Martins

Defesa: 14/04/2009

Introdução: $\mathrm{O}$ trauma é a principal causa de mortalidade no mundo, principalmente na faixa etária de maior produtividade, e reduz a expectativa de vida mais do que o câncer ou as doenças cardíacas. $\mathrm{O}$ trauma facial pode ser considerado grave, em vista das suas conseqüências emocionais, possibilidade de deformidades, impactos econômicos no sistema de saúde e lesões cranianas associadas. Objetivo: Descrever a incidência, gravidade, etiologia, fatores predisponentes dos traumas craniofaciais atendidos no centro Hospitalar de Santo André, durante o ano de 1999, após a mudança do Código de Trânsito Brasileiro. Método: Este é um estudo transversal. As informações foram obtidas junto ao Serviço de Cirurgia Traumatológica Bucomaxilofacial do Centro Hospitalar de Santos André (CHSA) - São Paulo, durante o período de janeiro a dezembro de 1999 , com registro de prontuários de atendimentos de 9880 pacientes com urgência e emergências craniofaciais. Foram inclúdos no estudo os dados referentes ao uso dos dispositivos de segurança (cinto, capacete com e sem mentoneira), tipos de trauma faciais, gravidade das lesões, etiologia, ossos envolvidos e gênero (masculino e feminino). Foi realizada a análise descritiva e utilizados os testes de Qui-quadrado e teste de comparação entre duas proporções. O nível de significância foi de 5\%. Resultados: Durante o ano de 1999 fora atendidos no serviço de urgência e emergencia craniofaciais do CHSA 9880 pacientes, sendo que $2210(22,4 \%)$ apresentavam traumas da face ( $18 \%$ sexo feminino e $82 \%$ sexo masculino), e dentro deste grupo as fraturas faciais totalizam 917 (41,5\%) casos, distribuídos da seguinte maneira: 112 (12,2\%) fraturas Le Fort; 309 (33,7\%) fraturas da mandíbula; $70(7,6 \%)$ fraturas alveolares e múltiplas; 248 (27\%) fraturas nasais; 163 (17,8\%) fraturas do zigomático; 15 $(1,6 \%)$ fraturas da parede inferior da órbita. Tais fraturas distribuíram-se igualmente nos meses estudados $(p>0,05)$. Observa-se uma associação significativa entre etiologia e tipos de fraturas $(p<0,001)$, sendo que os acidentes de transito foram as principais etiologias relacionadas às fraturas dos ossos da face, totalizando $505(55,1 \%)$ das causas, seguido por agressões 307 (33,5\%) e outros 105 (11,5\%). A incidência de fraturas dos ossos da face nos acidentes automobilísticos ocorreu em $194(21,2 \%)$ casos, e em todos os acidentes não havia o uso do cinto de segurança. Já com relação aos acidentes motociclísticos ocorreram $260(28,3 \%)$ casos e todos com fraturas craniofaciais, onde 257 (98,9\%) indivíduos não utilizavam o capacete e $03(1,1 \%)$ utilizavam o capacete sem mentoneira $(p<0,001)$. As fraturas mais graves dos ossos da face foram decorrentes de acidentes de trânsito $(84,8 \%)$, seguido de agressão $(10,7 \%)(\mathrm{p}<0,001)$. Conclusão: O número de pacientes atendidos no Centro Hospitalar de Santo André, em decorrência de emergência e urgência craniofacial foi elevado. $\mathrm{O}$ gênero masculino foi o mais acometido. A principal etiologia foi o acidente de trânsito com veículos automotores. Dentre as fraturas da face,a mandibular apresentou a maior incidência.

\section{Avaliação do Retalho de Pericárdio Bovino Preservado em Glutaraldeído; Relacionado as Diferentes faces Quando Utilizado Como Remendo Vascular. Estudo Experimental em Suínos}

Autor: Wladmir Faustino Saporito

Orientadores: Prof. Dr. Eduardo Colombari e Prof. Dr. Adilson Casemiro Pires Defesa: 28/05/2009

As características de boa resistência, flexibilidade, facilidade de manuseio e disponibilidade tornaram o pericárdio bovino tratado pelo glutaraldeído um dos materiais biológicos mais amplamente utilizados em cirurgia cardiovascular. Nunca tendo sido estudada suas diferenças funcionais e o seu desempenho na forma de retalho, utilizado como remendo vascular e as possíveis diferenças entre as faces lisa e rugosa em contato com a corrente sanguínea. Foram operados 14 porcos jovens com peso entre $10,3 \mathrm{Kg}$ e $18,4 \mathrm{Kg}$ sendo 6 do sexo feminino e 8 masculino, nos quais foram cirurgicamente implantados 2 retalhos substituindo parcialmente a aorta abdominal; um com a face lisa (FL), outro com a rugosa (FR) voltada para a luz do vaso e um retalho justaposto ao peritônio. Os animais foram sistematicamente sacrificados com pós- operatório variando entre 4,5 a 8 meses e peso entre 75 a $109 \mathrm{Kg}$, sendo avaliados os retalhos quanto a sua dilatação em relação a parede da aorta, formação de fibrose de aposição interna e a calcificação do retalho, relacionadas à face voltada para a luz do vaso. As peças retiradas foram avaliadas macroscópica e microscopicamente e submetidas à análise estatística. A análise sobre dilatação do remendo em relação à aorta adjacente quanto à face de implante verificou-se diferença estatisticamente significativa onde a face rugosa apresentou menor índice de dilatação. Não houve diferença na intensidade e/ou incidência calcificação do externo quando comparadas as superfícies. $\mathrm{O}$ pericárdio bovino preservado em glutaraldeído não apresentou alterações em sua estrutura quando implantado com diferentes faces voltadas para a luz do vaso. Concluindo que a face rugosa, quando voltada para a luz do vaso favorece uma menor dilatação do retalho quando comparada aorta adjacente e uma melhor qualidade da camada de endotelização, não ocorrendo diferença na intensidade e/ou incidência calcificação do enxerto.

\section{Análise dos Pacientes Re-admitidos na Unidade de Terapia Intensiva de um Hospital Público}

Autor: Renata Cristina Cerqueira

Orientador: Prof. Dr. Celso Ferreira Filho

Defesa: 17/04/2009

Introdução: Nas últimas décadas a qualidade na assistência à saúde ganhou destaque, e a readmissão hospitalar dos pacientes especialmente nas unidades de terapia intensiva, tem sido objeto de freqüentes pesquisas dos profissionais da área. Objetivo: Analisar as características de pacientes re-admitidos em Unidade de Terapia Intensiva de um hospital público. Método: Este é um estudo transversal, com dados dos prontuários de pacientes clínicos e cirúrgicos, no período de janeiro a junho de 2006, nas Unidades de Terapia Intensiva de adultos pertencentes a um hospital de grande porte da rede pública do Estado de São Paulo. Foram selecionados 329 pacientes de acordo com os critérios de inclusão e exclusão, dos quais $50(15,2 \%)$ foram readmitidos em UTI. Foram obtidas informações demográficas, diagnósticos de internação e readmissão; medida da severidade da doença segundo o Acute Physiology and Chronic Health Evaluation (APACHEII); nível de cuidado diário oferecido na UTI, durante a internação com a aplicação do Therapeutic Intervention Scoring System (TISS-28); tempo de permanência e intervalo entre a alta e a readmissão. Primeiramente foram avaliados dois grupos (readmitidos e não re-admitidos), a seguir foi realizada a análise apenas no grupo re-admitido comparando-se a sua internação com a re-internação. Com as informações da primeira internação para avaliar o APACHE 11 e TISS os pacientes foram então divididos em quatro grupos (RNCV: paciente re-admitido com diagnóstico não cardiovascular, RCV: paciente re-admitido com diagnóstico cardiovascular, $\mathrm{CV}$ : paciente não readmitido com diagnóstico cardiovascular, NCV: paciente não re-admitido com diagnóstico não cardiovascular). Fo realizada a análise descritiva, testes de Qui-quadrado, de comparação entre duas proporções, U de Mann-Whitney, Wilcoxon, Kruskal-Wallis, comparações múltiplas de Tukey. O nível de significância foi de 5\%. Resultados: Dos pacientes re-admitidos $35(70,0 \%)$ obtiveram alta e $15(30,0 \%)$ foram a óbito (teste de comparação entre duas proporções: $\mathrm{p}<0,05)$. Podese observar que os grupos são homogêneos em relação ao gênero ( $>0,05)$, porém não em relação à idade. O grupo re-admitido apresentou idade maior $(64,7$ :t 18,1$)$ do que o não readmitido $(58,5$ :t 17,9$)(\mathrm{p}<0,05)$. A média APACHEII foi maior no grupo re-admitido $(13,5: t$ $5,1)$ do que no grupo não re-admitido $(11,8: t 5,8)(\mathrm{p}<0,05)$. Não houve diferença significativa para o TISS-28 entre os dois grupos $(\mathrm{p}>0,05)$. Quando se compara apenas os pacientes reinternados observa-se que a variável APACHEII foi superior na re-internação $(16,4$ :t 6,9) na UTI $(\mathrm{p}<0,05)$. As doenças cardiovasculares foram o principal diagnóstico na internação e re-internação $(\mathrm{p}<0,001)$. Para o TISS, observa-se pelo teste de Kruskal-Wallis uma diferença significativa entre os quatro grupos $(\mathrm{p}<0,001)$. Pelo teste de comparações múltiplas de Tukey, observa-se para a variável primeiro TISS que o grupo RNCV apresentou média maior do que os demais grupos $(\mathrm{p}<0,005)$, o grupo RCV apresenta média menor do que os grupos RNCV e NCV $(\mathrm{p}<0,005)$, o grupo NCV apresenta média maior do que o grupo CV $(\mathrm{p}<0,005)$. Para o APACHE 11, observa-se pelo teste de Kruskal-Wallis que há uma diferença estatisticamente significativa entre os quatro grupos $(\mathrm{p}<0,001)$. Pelo teste de comparações múltiplas de Tukey, observa-se para a variável APACHE que o grupo RNCV apresentou média maior do que o grupo CV $(\mathrm{p}<0,005)$, o grupo RCV apresenta média menor do que o grupo CV ( $<<0,005)$, o grupo NCV apresenta média maior do que o grupo CV ( $p<0,005)$. Conclusão: Os pacientes re-admitidos apresentaram idade mais avançada. Os pacientes re-admitidos com diagnósticos cardiovasculares, apresentaram menor TISS do que os pacientes com diagnósticos não cardiovasculares re-admitidos e não readmitidos. Os pacientes re-admitidos com diagnósticos cardiovasculares apresentaram APACHE maior do que os pacientes não readmitidos com diagnósticos cardiovasculares. 


\section{Comportamento dos Índices Triglicérides/HDL-Colesterol, Homar-ir e Quick no Diagnóstico da Síndrome Metabólica}

Autor: Joffre Nogueira Filho

Orientadores: Prof. Dr. Francisco Macedo Paschoal e Prof. Dr. Ricardo Peres do Souto

A síndrome metabólica é um quadro nosológico com altas taxas de morbidade e mortalidade. Esta síndrome é a co-morbidade da obesidade que apresenta maiores danos à saúde po aumentar a predisposição, para doenças cardiovasculares, o diabete tipo 2, a hipertensão arterial sistêmica e a síndrome do ovário micropolicístico. Nosso Trabalho comparou um grupo de pacientes portadores da síndrome metabólica (SM), diagnosticado pelo critério clínico aceito pela literatura e um grupo controle sem a patologia. Comparou os valores dos critérios para o diagnóstico, pressão arterial e circunferência da cintura, as dosagens em jejum da trigliceridemia, do HDL-colesterol e da glicemia, entre os grupos. Comparamos nos dois grupos os índices diagnósticos Homa-IR, Quicki e o quociente entre os valores obtidos pela dosagem plasmática em jejum dos triglicerídeos (TG), sobre os valores das dosagen em jejum do HDL-colesterol (HDL-C), na utilização diagnóstica da síndrome metabólica. Demonstramos que o conjunto dos critérios utilizados para o diagnóstico desta síndrome, apesar de diferentes estatisticamente emtre os grupos portadores da síndrome e os controles e, em seu conjunto, efetivamente diagnosticarem a resistência à insulina, não são isoladamente suficientes para o diagnóstico da referida síndrome. Defesa: 03/07/2009

\section{Avaliação de Fatores de Risco Relacionados à Giardíase em Crianças Menores de 2 anos, em uma Região do ABC Paulista}

Autor: Isabel Cristine Fernandes

Orientador: Prof. Dr. Wilson Roberto Catapani

Defesa: 03/07/2009

Introdução: A etiologia parasitária é pouco considerada como causa de doença em lactentes Objetivo: Estimar a prevalência e fatores de risco para a giardíase em crianças até 2 anos de idade, em uma região do $\mathrm{ABC}$ paulista. Método: Estudo transversal seqüencial de uma amostra incluindo 80 crianças de ambos os sexos. Com até 24 meses de idade, provenientes de 4 bairros da região de Capuava. Os fatores de risco analisados foram: idade, sexo, grau de nutrição, tempo de gestação, idade da mãe, renda e escolaridade da mãe, período de permanência na creche, densidade habitacional (moradores/cômodo), bairro de procedência, tratamento de água de beber, presença de giardíase nos cuidadores. Cada criança forneceu 3 amostras de fezes para exame. Os dados foram analisados por regressão logística múltipla (RLM), com nível de significância adotado de alfa $\leq 5 \%$. Resultados: Dentre as 80 crianças estudadas identificamo 16 crianças com Giárdia (20\%). Foram relacionadas individualmente à presença de giardíase, de modo significante, a faixa etária da criança (razão de risco $16,81, \mathrm{p}=0,009$, IC 1,98-142,39 para criança entre 17 e 24 meses em relação às com menos de 8 a 16 meses), tempo de gestação (razão de risco $0,14 \mathrm{p}=0,005$, IC $0,03-0,55$ para gestação de 9 meses em relação a menos de 9 meses), período de permanência na creche (razão de risco 8,46, $\mathrm{p}=0,001$, IC 2,29-31,17, para crianças na creche em período integral em relação às que freqüentam a creche no período parcial) e diferença entre a idade da criança e a duração do aleitamento materno exclusivo (razão de risco de 21,35, p= 0,005, IC 2.51-181,42 em relação as crianças que apresentaram esta diferença em até um ano). Combinadas entre si, sobressaem a diferença entre a idade da criança e a duração do aleitamento materno (razão de risco 20,05, p=0,011, IC 1,95-2005,5 em relação a diferença de 1 ano) e período na creche (razão de risco 2,59, p= 0,24 IC 0,52-12,65 em relação as crianças que ficam na creche em um período parcial). Conclusão: A prevalência de giardíase foi de $20 \%$, sendo $1,25 \%$ ( 0 a 6 meses de idade), $1,25 \%$ ( 7 a 12 meses), $6,25 \%$ ( 13 - 18 meses) e 11,2\% (19- 24 meses). O risco de giardíase é 20,05 vezes maior nas crianças cuja diferença entre a idade e o tempo de amamentação é superior a um ano, do que naquelas com esta diferença inferior a um ano, ou as que ainda estão em aleitamento materno exclusivo.

\section{Avaliação do Método de Quimioluminescência na análise de Homocisteína Plasmática e sua Comparação com 0 Método de HPLC em amostras de Crianças}

\section{A Influência dos Ácidos Graxos Livres Circulantes na Resistência à Insulina e no Hipercortisolismo Endógeno Crônico (Doença de Cushing)}

Autor: Ana Teresa Mana Gonçalves Santomauro

Orientador: Prof. Dr. Ricardo Peres do Souto

Defesa: 05/08/2009

O objetivo deste estudo foi investigar o papel dos ácidos graxos livres (AGL) na resistência à insulina e na tolerância à glicose que observamos muitas vezes na síndrome de Cushing. Acipimox (AC) ou placebo foi administrado durante a noite a 42 mulheres, divididas em cinco grupos: normais $(\mathrm{NC} ; \mathrm{n}=8)$, obesas $(\mathrm{OB} ; \mathrm{n}=10)$, obesas com intolerância à glicose (IGT; $n=8$ ), obesas portadoras de diabetes (DM; $n=9$ ), e doença de Cushing (DC; $n=7$ ). Após o uso da medicação as pacientes realizaram calorimetria indireta durante teste oral de tolerância à glicose e um clamp euglicêmico hiperinsulinêmico em dias diferentes. O grupo DC apresentava níveis maiores de AGL no basal e após sobrecarga de glicose, quando comparado com o grupo NC e 08. Após AC os níveis de AGL se reduziram em todos os grupos, com nenhuma diferença entre eles. A redução dos AGL se acompanhou pela diminuição dos níveis de glicemia plasmática em todos os grupos, exceto no grupo IGT, e os níveis de insulina diminuíram em todos os grupos, exceto nas NC. A oxidação basal de glicose foi similar em todos os grupos e aumentou após o uso de AC. Na calorimetria o consumo de glicose pela via não oxidativa foi menor, com significado estatístico, no grupo DC quando comparado com os outros grupos e aumentou após o AC nos grupos NC e DM, mas não no grupo DC. No estudo com clamp, o grupo DC apresentou a menor taxa de infusão de glicose (TIG), em comparação com os grupos NC e OB. Após AC todos os grupos mostraram aumento na sensibilidade à insulina (SI), mas nos pacientes do grupo DC, observamos uma GIR menor do que a observada em todos os outros grupos. Concluímos que os AGL têm um papel na homeostase alterada à glicose nos pacientes com DC, e o AC parcialmente reverteu a resistência à insulina, observada neste grupo.
Autor: Thaís Moura Gascón

Orientador: Prof. Dr. Fernando Luiz Affonso Fonseca

Defesa: 18/09/2009

A homocisteína é um subproduto do metabolismo da metionina que utiliza como co-fatores em seu metabolismo o folato, a vitamina B12 e a vitamina B6. Este aminoácido tem recebido muita importância como um novo e importante fator para investigação em uma variedade de disfunções como falência crônica do coração, efeitos trombóticos e aterogênicos, estresse oxidativo, diabetes do tipo I, osteoporose, obesidade e homocistinúria. Um estudo observacional prospectivo foi realizado com o objetivo de determinar níveis plasmáticos de homocisteína para comparação dos métodos de análises de HPLC e quimioluminescência em amostras obtidas de 185 crianças em idade escolar, residentes no município de Santo André, livres de doenças crônicas, inflamatórias e ausência de desenvolvimento puberal. Os resultados foram distribuídos em percentis e os valores de referência foram determinados na faixa etária entre $7 \mathrm{e} 9$ anos, com valores de 2,0 a $9,9 \mu \mathrm{mol} / \mathrm{L}$, obtendo um $\mathrm{r}=0,821$ e $\mathrm{p}<0,0001$. Constatouse que o método quimioluminescente para a determinação de homocisteína é compatível com o HPLC quando ambos são aplicados em amostras de crianças em idade escolar. Importante relação foi obtida quando ambos os métodos foram comparados o que permite a ampla utilização da investigação desse aminoácido como fator de risco em doenças cardíacas. Como não há muitos estudos demonstrando a prevalência de hiperhomocisteinemia nesta faixa etária os valores baseiam-se em estudos anteriores. 


\section{Desenvolvimento de Modelo Animal para utilização de Terapia Fotodinâmica no tratamento do Melanoma}

Autor: Marcio Wagner

Orientadora: Profa. Dra. Maria Aparecida da Silva Pinhal Defesa: 09/10/2009

O melanoma é um tumor maligno, de alto grau de agressividade, derivado de melanócitos. Ainda hoje, o único tratamento eficaz é a retirada cirúrgica nos estágios precoces, não estando disponíveis outras formas de tratamento. A terapia fotodinâmica ou PhotoDynamic Therapy (PDT) é um processo no qual moléculas fotossensibilizadoras expostas a uma fonte de luz específica captam e transferem energia para moléculas vizinhas de oxigênio, produzindo compostos eletricamente excitados, os radicais livres, principalmente o oxigênio singlete que promove o dano exclusivo às células tumorais. Tardivo, na Faculdade de Medicina do $\mathrm{ABC}$, desenvolveu um aparelho de baixo custo, batizado de RL 50, que emitia luz vermelha policromática que fotoestimulava o azul de metileno, corante escolhido como fotossensibilizador devido à sua grande afinidade à melanina. Esse sistema foi utilizado em uma paciente com seis lesões de melanoma metastático com resposta total em cinco lesões. O objetivo do presente estudo é desenvolver um modelo animal para o tratamento do melanoma, utilizando como fonte de luz o RL 50 e como fotossensibilizador o azul de metileno e, posteriormente, avaliar a eficácia do tratamento.

\section{A Humanização da Medicina e a Medicina Humanística}

Autor: Fernando Soares Guedes

Orientador: Prof. Dr. Wilson Roberto Catapani

Defesa: 16/10/2009

Este estudo inicia-se com uma reflexão sobre a questão da humanização na medicina. Desta reflexão depreende-se que a medicina só será realmente humanizada quando re-incorporar o saber humanístico ao saber científico. A dimensão humanística é fundamental para a compreensão dos fenômenos pois é ela quem dá sentido e significado à existência e ao sofrimento humano. Com esta perspectiva, a doença é visualizada de forma plena e integrad à história de vida do indivíduo. O objetivo é superar o modelo biomédico e integrá-Io a uma prática que retire o enfoque exclusivamente orgânico da doença e pense o processo do adoecer com as suas múltiplas dimensões e causalidades. Deste modo consegue-se transcender a questão biológica e alcançar a verdadeira evolução que está na pluralidade epistemológica, que será alcança da com a integração da medicina pré-moderna, com suas bases humanistas e religiosas, com a medicina moderna, com suas bases empíricas e científicas. Este estudo aponta caminhos para alcançar este objetivo na prática clínica diária. Mostra como buscar a causa do adoecimento não apenas nos aspectos biológicos, mas no que há de essencialmente humano no homem, na alma.

\section{Pico de Fluxo Expiratório em Crianças e Adolescentes Saudáveis}

Autor: Fernanda Regina Campos Radziavicius

Orientador: Prof. Dr. Luiz Carlos de Abreu

Defesa: $29 / 10 / 2008$

Diversas doenças pulmonares resultam em uma variação do grau de obstrução para o fluxo aéreo na árvore traqueobrônquica, com isso, técnicas para estimar o grau de severidade desta obstrução são de extrema utilidade a fim de avaliar o desajuste funcional e os resultados das medidas terapêuticas. Sendo assim, o estudo tem por finalidade descrever valores de pico de fluxo expiratório (PFE) em crianças e adolescentes saudáveis de cinco a dez anos de idade. Após aprovação do Comitê de Ética de Pesquisa em Seres Humanos da Faculdade de Medicina do ABC - FMABC, 2.312 crianças e adolescentes saudáveis com idade entre cinco a dez anos oriundos de nove escolas da rede pública estadual e nove escolas da rede privada do município de São Bemardo do Campo foram avaliados. Destes, 1.942 fizeram parte do estudo, no qual foram submetidos à coleta do PFE através do Mini Wright Peak Flow Meter da Clement Clarke International Ltda, como também, à mensuração da altura por meio do Estadiômetro Profissional Sanny, afim de possíveis correlações. Dentre os resultados encontrados, observamos diferenças significantes nos valores encontrados de PFE com relação a variável sexo e tipo de escola avaliada, sendo observado, maiores valores no sexo masculino quando comparado ao feminino e nas escolas da rede privada em relação à da rede pública, tendo como valores médios: 244 para $212 \mathrm{~L} / \mathrm{min}$ e 258 para $210 \mathrm{~L} / \mathrm{min}$, respectivamente. Através do Coeficiente de Spearman, observamos correlação linear com os valores de PFE e a variável altura e idade, além de confirmarmos a existência de diferença entre os valores de PFE com relação ao sexo, como observado nos estudos previamente realizados, conseguindo assim, descrever através da Análise de Regressão Múltipla valores de PFE em crianças e adolescentes saudáveis de cinco a dez anos de idade do Município de São Bemardo do Campo, com o decorrer da idade e altura em ambos os sexos.

\section{Tese: "Distribuição Proporcional de Dentes Retidos no ABC Paulista - Brasil".}

Autor: Renato Albieri

Orientadora: Profa. Dra. Olinda do Carmo Luiz

Defesa: 10/11/2009

Introdução: A retenção dentária ou o atraso no irrompimento dentário pode ser um fenômeno comum e causar complicações locais preocupantes como reabsorções de coroas e raízes dentárias adjacentes, fraturas mandibulares, dores orofaciais, comprometimentos periodontais, formação de cistos, tumores odontogênicos e formação de cárie nos dentes adjacentes. Objetivo: O objetivo do presente estudo foi avaliar a distribuição proporcional de dentes retidos e estimar o grupo de elementos dentários mais freqüentes na retenção dentária, em um período de 24 meses, na cidade de Santo André e fatores relacionados a ela. Materiais e Métodos: Este é um estudo observacional seccional realizado na cidade de Santo André-SP através de radiografias de indivíduos de ambos os sexos, com idades de 14 a 60 anos, separadas por sexo e faixas etárias, no período de janeiro de 2005 a dezembro de 2006, que procuraram atendimento odontológico por motivos distintos. Resultado: Foi verificado através do estudo que a retenção dentária é um problema de alta distribuição proporcional nos indivíduos jovens da amostra, principalmente nas faixas etárias dos 14-16 anos e não houve uma predisposição quanto ao sexo. Houve uma diminuição da distribuição proporcional de elementos dentários retidos com o aumento da faixa etária. Os terceiros molares foi o grupo de dentes que mais apresentou retenção dentária, sendo responsável por $94,7 \%$ de todas as retenções e foi observado em $45 \%$ das radiografias analisadas, seguido dos caninos. Foi observado que a faixa etária de maior distribuição proporcional de terceiros molares retidos foi de 17-21 anos e de 22-26 anos respectivamente, não havendo diferenças entre ambos os sexos ou entre os arcos superiores e inferiores e ainda quanto a sua localização nos arcos dentários. A freqüência de caninos retidos encontrada foi bem menor que a de terceiros molares retidos. Houve uma maior frequiência de caninos retidos superiores em relação aos caninos retidos inferiores, não existindo diferença significativa entre os lados direito e esquerdo. Não houve diferenças entre os sexos e suas faixas etárias na retenção dos caninos. Conclusão: $\mathrm{O}$ grupo dos terceiros molares foi o que mais apresentou retenção dentária, sendo responsável por $94,7 \%$ das ocorrências. 
Mensuração da Superfície Articular da Cabeça do Úmero em Cadáveres e Exames de Ressonância Nuclear Magnética: Estudo em 83 ombros

Autor: Eric Strose

Orientador: Prof. Dr. Edison Noboru Fujiki

Defesa: $19 / 11 / 2009$

O objetivo deste trabalho foi mensurar as dimensões da superfície articular da cabeça (SAC) do úmero 83 ombros e avaliar se seu formato é esférico ou elíptico. Realizamos as mensuraçõe de maneira direta com paquímetro manual em $68 \mathrm{SAC}$ do úmero de cadáveres frescos os quais denominamos Grupo I e de maneira indireta em cortes de exames de ressonância nuclear magnética de 15 pacientes de nosso ambulatório os quais denominamos Grupo II. No Grupo I, após dissecação e limpeza total das partes moles do úmero proximal 34 cadáveres ( 68 ombros), determinou-se a maior distância entre os extremos da cartilagem articular no sentido súpero-inferior(SI) e antero-posterior(AP), e a espessura da cabeça do úmero(H). No Grupo II as mesmas distâncias foram aferidas com programa de computador. Calculou-se ainda, em ambos os grupos através de fórmula matemática, o raio de curvatura do setor circular da SAC do úmero nos dois planos (RSI e RAP). A média das distâncias SI, AP e $\mathrm{H}$ aferidas no Grupo foram respectivamente de 43.50, 40.94 e $19.12 \mathrm{~mm}$. A média dos raios de curvatura RSI e RAP foram respectivamente 22.15 e $20.75 \mathrm{~mm}$. A média das distâncias SI, AP e H aferidas no Grupo II foram respectivamente de $43.67,41.73$ e $18.40 \mathrm{~mm}$. A média dos raios de curvatura RSI e RAP foram respectivamente 22.27 e $20.98 \mathrm{~mm}$. Os valores encontrados para os diâmetros súpero-inferior e antero-posterior, assim como seus respectivos raios de curvatura, são estatisticamente diferentes, tanto quando estudados em cadáveres como quando estudados em ressonância magnética nos fazendo acreditar que a superfície articular da cabeça do úmero não é uma secção de esfera mas sim de uma elipse.
Fatores associados ao tempo de chegada de Mulheres ao Serviço de Saúde após Violência Sexual

Autor: Maria Auxiliadora Figueredo Vertamatti

Orientador: Prof. Dr. Caio Parente Barbosa

Defesa: 24/11/2009

Objetivo: Descrever as características sócio-demográficas e clínicas de vítimas de violência sexual e sua associação com o tempo decorrido entre a agressão sexual e a chegada ao serviço de saúde. Método: Estudo retrospectivo de 439 casos por livre demanda, da população de mulheres atendidas pelo Programa de Atenção à Violência e Abuso Sexual de São Bernardo do Campo, São Paulo (PAVAS-SBC), no período de 2000 a 2007. Resultados: De 439 pacientes incluídas, 374 chegaram antes de 72 horas ao hospital. A média de idade foi de 24,5 anos, a maior parte $(45,1 \%)$ cursava ou havia concluído o segundo grau. A penetração vaginal foi a ocorrência mais comum, sendo exclusiva em $43,9 \%$ dos casos, enquanto que a associação desta com penetração anal ou oral ocorreu em $31,4 \%$ dos casos. Foram estatisticamente significantes para a chegada após 72 horas da agressão: a ausência de trauma não genital ( $\mathrm{OR}=2,58$; IC95\%: $1,04 ; 6,38)$, a não realização de denúncia policial $(\mathrm{OR}=2,74 ; \mathrm{IC} 95 \%: 1,58 ; 4,78)$ e o agressor conhecido (OR=0,51; IC95\%: 0,28; 0,96). Interpretação dos Conclusão: $O$ traumatismo não genital e a denúncia policial foram protetores para as vítimas, trazendo-as ao hospital dentro das primeiras 72 horas após a ocorrência; já o agressor conhecido foi fator determinante no atraso à chegada ao serviço de saúde. Políticas públicas para capacitação, divulgação e integração entre os setores envolvidos na abordagem deste tipo de violência podem reduzir as complicações dela decorrentes. 